Dicenda. Cuadernos de Filología Hispánica

ISSN: 0212-2952

http://dx.doi.org/10.5209/DICE.57703

\title{
La protagonista femenina de las Coplas de Puertocarrero: relevancia escénica y pro-feminismo. Comparación con otras voces femeninas de los cancioneros
}

\author{
M. Mercedes Guirao Silvente ${ }^{1}$
}

Resumen. Este artículo pretende descubrir la relevancia escénica de "Ella"; protagonista de las Coplas de Puertocarrero. Para ello, no sólo se analiza su papel dentro de esta obra, sino en relación con otras voces de la mujer en aquella sociedad en transformación de finales del XV, donde las damas habían alcanzado un gran protagonismo.

Palabras clave: voz femenina; Cancioneros; Coplas de Puertocarrero; teatro medieval.

\section{[es] The female main character in Coplas de Puertocarrero: scenic relevance and pro-feminism. Comparison with other feminine voices in "cancioneros"}

\begin{abstract}
This article tries to discover the scenic relevance of "Ella" ("She"); the main character in the Coplas de Puertocarrero. To this purpose, her role is not only analyzed in the work, but in relation to other female voices in the $15^{\text {th }}$ century "Cancioneros". Her insolent realism demystifies the expected courtly speech of her conversational partner and, especially, it shows a clear recognition of women in the changing society in the late $15^{\text {th }}$ century, when ladies played a prominent role.

Keywords: female voice; Cancioneros; Coplas de Puertocarrero; medieval theatre.
\end{abstract}

Sumario. 1. La victoria de Ella sobre Puertocarrero 2. Ella frente a las voces femeninas de otros diálogos amorosos de cancionero 2.1. Fernán Sánchez Calavera [ID1663] y [ID1664] 2.2. Johan de Duenyas [ID2492] 2.3. Francisco Imperial [ID 1376]. 2.4. Fray Diego de Valencia de León [ID1639] 3. Conclusiones

Cómo citar: Guirao Silvente, M.M. (2017). La protagonista femenina de las Coplas de Puertocarrero: relevancia escénica y pro-feminismo. Comparación con otras voces femeninas de los cancioneros, $D i$ cenda. Cuadernos de Filología Hispánica, 35, 131-152.

UNED

merceguisil@hotmail.com 


\section{La victoria de ella sobre Puertocarrero}

Las Coplas de Puertocarrero, recogidas en el Cancionero General y en el Cancionero de Londres ${ }^{2}$, presentan, como se ha hecho notar a menudo, un evidente carácter dramático3:

La obra, por su variedad de situaciones escénicas y de personajes, así como su diálogo muy vivo y animado, puede ser tenida como un claro experimento teatral. El tratamiento jocoso y procaz del discurso y los comportamientos amorosos la inscriben en el mismo género del teatro cortesano que el Diálogo del Viejo, el Amor y la Mujer hermosa. Teatro que, como parece desprenderse de estas obras, tomaba como asunto central la desarticulación literaria, en clave realista y burlesca, del código amoroso cortés, teñido todo de un tono de desengañado pesimismo (Pérez Priego, 2009: 86-87).

Ofrecen, en efecto, una tensa y acalorada batalla dialéctica entre dos personajes: Puertocarrero y la señora objeto de su devoción amorosa -a la que, observando el anonimato cortés, se denomina con el pronombre "Ella"4-. Y, precisamente, es la dama la que, lejos del papel frío y pasivo que se reserva a la mujer en la literatura cortesana, se alza, progresivamente, con el protagonismo del diálogo, desplazando al caballero y contribuyendo, con su sorprendente dinamismo verbal y físico, a la posible representación del texto. De esta forma, salta de su pedestal cuando le conviene y es, finalmente, la que gana el debate amoroso, a través de una violenta confrontación entre su visión práctica y el baldío idealismo de Puertocarrero. Como señala Monica von Wunster (1996: 32):

[...] si trata infatti di un'autentica dichiarazione amorosa sviluppata secondo le regole della convenzione cortese.

Ma sin dall'inizio appare altrettanto chiaro che la dama non intende stare al gioco. Infatti essa ridicolizza la risposta del poeta con l'ironia che le proviene dall'affrontare in termini logici, e quindi reali, i contenuti metaforici delle topiche cancioneriles.

2 El texto ha llegado hasta nosotros muy deturpado, con lagunas y omisiones (Pérez Priego, 2009: 235) y hay importantes diferencias entre las versiones recogidas en ambos cancioneros e, incluso, entre las que se registran en la historia editorial del Cancionero General a lo largo del siglo XVI (véase Moreno, 2001). Seguimos la edición de Pérez Priego, que corrige el texto del Cancionero General en sus "errores evidentes" y desarrolla las abreviaturas p., e., x., marcando y distribuyendo las intervenciones de estos tres personajes (véase Pérez Priego, 2009: 235 y ss.). Todas las citas que hacemos de las Coplas de Puertocarrero están tomadas de esta edición.

3 Existe, no obstante, cierta discrepancia sobre la naturaleza dramática de las Coplas. Lázaro Carreter (1965), así como Pérez Priego (2009) o Manuel Moreno (2001) han destacado sus valores teatrales. Otros especialistas del teatro medieval, como Ana Ma Álvarez Pellitero (1990) y Ronald E. Surtz (1992), en cambio, prescinden de ellas en sus respectivas ediciones.

$4 \quad$ En la rúbrica inicial se lee: “Coplas que fizo Puerto Carrero porque passando un día por una calle donde su dama estava con una compañera suya, y también tercera dél, que se llamava Xerez, las quales él no avía visto, fue llamado por su señora y començaron a hablar los dos, y algunas vezes ella burlando dél y desfraçéndole, y vuelve la habla a su compañera, donde él toma argumento para hazer este diálogo, en el que se introduze Puerto Carrero, [X]erez, Ella, que es su señora, y Lope Osorio, hermano de la señora. Y comiença desta manera" (Pérez Priego, 2009: 237). 
La acción, de cuyo desarrollo nos pone al corriente el autor en las breves rúbricas que se van alternando con el diálogo de los personajes, o bien los personajes mismos a través de lo que dicen o hacen en escena, comienza cuando Ella, al ver a Puertocarrero por la calle, lo hace subir por una escala a su patio, para divertirse con su turbación. Éste deja de ir a cazar -el otro gran pasatiempo, junto al amor, del caballero cortesano-, para cumplir la voluntad de su amada, aunque sospecha que nada bueno le aguarda de quien no recibe siempre sino frialdad.

En esta parte introductoria, que enmarca la conversación que se va a desarrollar entre Puertocarrero y Ella, aparece un tercer personaje también característico de la literatura cortés, la tercera-confidente Xerez, que tiene la misión dramática de darnos a conocer las intenciones de Ella al llamar al caballero y la de acentuar, aún más, la pícara malicia de la dama, apiadándose de Puertocarrero y asombrándose de lo que su amiga está dispuesta a hacer:

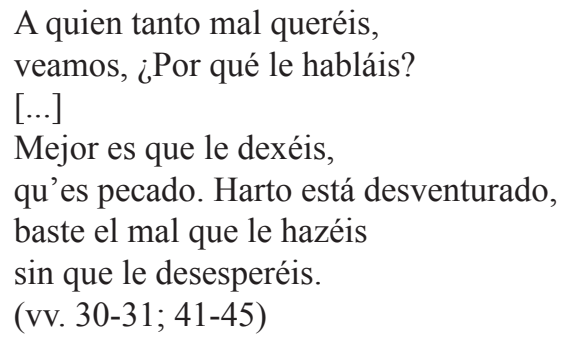

Xerez se esconde, a instancias de la dama, y será testigo mudo de la conversación entre los dos protagonistas, pudiendo comprobar las contradicciones del amor cortés y reírse de sus absurdos, tal y como Ella pretende que hagamos -junto a la tercera-, todos los receptores. De este modo, ya anticipa, con esas palabras sarcásticas que dirige a Xerez, lo que vamos a ver en escena:

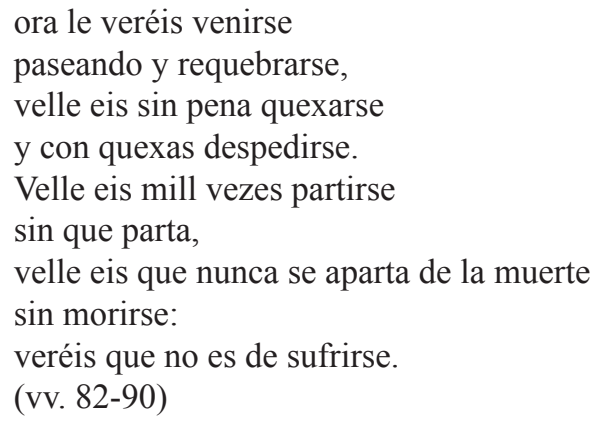

Frente al ensimismamiento característico del amante cortés: "No sé do voy, / ni do vengo ni do estoy, / ni sé de mi parte agora" (vv. 2-4), se alza la resolución y seguridad en sí misma de Ella. Ante los gemidos amorosos de Puertocarrero, de sobra conocidos y repetidos -hecho que le da ventaja en su inteligente argumentación-, adopta un tono realista, que la lleva a desmontar todo el edificio amoroso de la literatura cortesana.

Así, se muestra escéptica ante la afirmación de Puertocarrero de que su triste vida (condenado a amar a quien no merece) es peor que la muerte y lo tacha de egoísta 
por querer que ella sufra de la misma manera (vv. 244-245), burlándose de su inexperiencia amorosa: "Eso más fue d'estudiante/ que de discreto en amores" (vv. 316317) y de los disparates que contienen las antítesis que se encadenan en su discurso amoroso, continuamente dedicado a describir lo penoso de su estado. La dama llega, incluso, a rechazar, en un momento de gran movilidad escénica, el contacto físico con el caballero:

$\begin{array}{ll}\text { Ella } & \text { ¿Mas de veras decís algo? } \\ \text { Puerto Carrero } & \text { No, ni sé si entro ni salgo. } \\ & \text { Si'stó dentro, si’stó fuera. } \\ & \text { Ni sé si prueve a salirme } \\ & \text { o si estaré, } \\ & \text { ni pienso lo que haré, } \\ & \text { ni bien oso despedirme, } \\ & \text { ni’stó ni quiero partirme. } \\ & \text { Y pues que yo no m’entiendo, } \\ & \text { no es mucho que nom'entiendan } \\ & \text { ni que mis males me ofendan, } \\ & \text { pues los busco y los enciendo. } \\ & \text { ¿Dónde se cosió esse guante? } \\ & \text { ¿Qué deslates! } \\ & \text { ¿Vienen ya los disparates? } \\ & \text { Pues yo’s do fe que m’espante } \\ & \text { si m’echáis el pie delante. } \\ & \text { (vv. 416-432) }\end{array}$

Puertocarrero, pese a la actitud hostil que ante el amor muestra la dama desde el mismo inicio, hace desfilar otros muchos tópicos corteses propios de la lírica de cancionero. Así, la identificación del amante con un prisionero:

Miro que me tenéis preso

con prisiones que soltarme es la cadena

y estar fuera de esta pena,

péname tanto apartarme

qu'es pena para matarme.

(vv. 490-495)

También aparece la característica asociación amor-fe: “...qu’es mi fe vuestra cativa/aunque más muertes reciba" (vv. 584-585). Y son frecuentes las críticas a la incomprensión y dureza de la dama: "...do ay tanta crueza/lo mejor es más tristeza" (vv. 278-279).

Pero todo resulta en balde, pues la astuta Ella le va rebatiendo todas sus afirmaciones en una actitud de aburrimiento y hartazgo que en el verso 550 la lleva a asestarle un golpe mortal, en lo que podemos considerar el clímax de la obra, mostrándole lo falso que le ha sonado todo su discurso:

quien de verdad se enamora

su conorte 
no lo rige por su norte:

su amiga y su señora

tiene por su guiadora.

(vv. 554-558)

Evidenciando, después, que no cree en su sufrimiento:

a quitar ociosidad

os entrastes;

pues pasatiempo buscastes,

no fijáis necesidad,

que es tocar en liviandad.

(vv. 626-630)

El caballero reconoce que ha sido vencido ante la clara inteligencia de su rival:

qu'es tan alta

vuestra discreción que falta

en mí saber, y caresce

la respuesta que merece.

(vv. 564-567)

No obstante, Ella no se conforma con que Puertocarrero reconozca su elocuencia y superioridad y se dé por perdedor en la contienda. En el desenlace de la obra, le pide fruta para la merienda, aprovechando que éste se dice su servidor y lo hace burlándose del secreto que requería el amor cortés. Así, ante la preocupación del caballero por cómo ha de hacerle llegar la comida sin levantar sospechas, la dama responde con una gran dosis de sarcasmo y frescura:

$\begin{array}{ll}\text { Puerto Carrero } & \text { ¡Por vida de quien se fuere! } \\ & \text { mas no sé qu’enbíe } \\ & \text { ni en qué ni de quién me fíe. } \\ & \text { El qué, de quanto viniere } \\ & \text { el en qué, doquier que venga } \\ & \text { el con quién, } \\ & \text { quien quiera lo traerá bien } \\ & \text { en tal que no se detenga } \\ & \text { el tanto que no se avenga. } \\ & (\text { vv. 649-657) }\end{array}$

Recordemos que la comida era considerada un lujo en la Edad Media, pues -tal y como explica Jacques Le Goff (1999: 205)- "la ostentación de la comida expresa un comportamiento de clase". Puertocarrero, que tanto orgullo caballeresco despliega a lo largo de toda la obra, vuelve aquí a caer en las redes de su contrincante, que tan bien conoce sus debilidades, y no duda en enumerar los ricos manjares que tiene en su casa para no pasar por pobre. De esta forma, se da a la escena un costumbrismo que la aleja claramente del idealismo propio de la literatura cortés: 


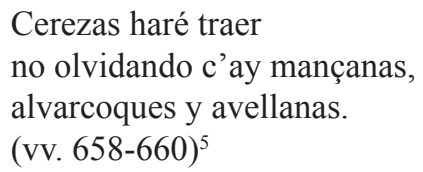

Encontramos aquí un tímido intento vengativo contra un futuro marido de la dama, que saca por breves instantes al caballero de su sufrido papel para mostrarnos un pícaro ingenio que lo lleva a jugar con el sentido de la palabra "cornezuelo" y a ofrecerle fruta verde -aunque más que nada sus guindas están verdes de envidia-:

\begin{tabular}{|c|c|}
\hline Puerto Carrero & [...] ¿ay más frutas que pidáis? \\
\hline Ella & Cornezuelos. \\
\hline Puerto Carrero & $\begin{array}{l}\text { Préndasse en esos anzuelos } \\
\text { el marido qu'esperáis, } \\
\text { pues tal fruta demandáis. }\end{array}$ \\
\hline Ella & $\begin{array}{l}\text { Guindas ay, mas son verdes. } \\
\text { ¡Ieshú, qu'emportuno estáis! } \\
\text { Anda, íos. Con tal que os vais, } \\
\text { embiáme lo que quisiéredes. } \\
\text { (vv. 662-670) }\end{array}$ \\
\hline
\end{tabular}

Ante el nuevo desprecio de la dama, el caballero vuelve a retroceder y descubre el tesoro culinario que guarda en su casa, para insinuarse y volver a atraer su golosa atención: "Pues lo mejor se me olvida:/natas ay" (vv. 671-672). Ella, haciendo caso omiso del simbolismo erótico de tal alimento, aprovecha rápidamente este momento para lanzar sobre Puertocarrero toda su violencia y desfachatez. Ordena a su criada Leonorcica que no pierda tiempo en recogerlas y a éste que corra a dárselas, en un momento muy ágil, fingiendo que la apremia un hambre atroz:

¡Leonorcica, corre, vay!

¿Vellaca, no eres venida?

Dadgelas, por vuestra vida.

(vv. 673-675)

Ella, dado su carácter realista, no quiere un cortejo basado en meras lisonjas, que le suenan a vacías: "iqué descuento! /Echáis palabras al viento" (vv. 573-574), sino algún placer más concreto, como el de la comida. Recordemos, en este sentido, cómo Pármeno y Sempronio se apresuran a vaciar la despensa de Calisto, enumerando los manjares que aportarán a sus amantes, Elicia y Areúsa, mientras este último, en tanto que prototípico caballero cortés, se desentiende de cuanto le rodea (Auto VIII, Escena $3^{\mathrm{a}}$ ). Puertocarrero asume -ahora sí-, su derrota:

\footnotetext{
Estos versos recuerdan la enumeración de delicias que la alcahueta hace a Doña Endrina en el Libro de buen amor, para convencerla de visitar su tienda, donde la aguardan los placeres del amor: "Muchas peras e duraznos, ¡qué çidras e qué mançanas!/ ¡Qué castañas, qué piñones e qué muchas avellanas!” (Blecua, 1998: 210, vv. 823-824). Sin embargo, a Ella no parece interesarle el significado simbólico de tales manjares, sino éstos en sí mismos, rompiendo con ese lenguaje figurado que pretende el caballero y que evidencia la urgencia sexual que ocultaba el etéreo discurso cortés.
} 
Siéntome desesperar

porque mandáis apartarme

con voluntad de matarme

mas que no de merendar.

(vv. 685-688)

La humillación del caballero que no puede servirla como amante, sino sólo como suministrador de viandas para la merienda, es absoluta. Proclama, con el anuncio de su muerte, el triunfo final de la razón sobre el sentimiento, de lo material sobre lo espiritual, en esa alternancia o enfrentamiento que señalábamos entre los dos personajes, y que deja la escena bañada de un hálito de desengaño y melancólica tristeza:

Ya me voy de donde quedo,

voyme sin poder partir

con certeza de morir

tomo el empresa sin miedo.

(vv. 694-696)

El personaje femenino refleja -dada su desenvoltura y su relevancia en escenael hastío ante unos convencionalismos amorosos ya agotados y muestra, en cierta forma, una función muy parecida a la de Puertocarrero-autor. Abre y cierra la acción cuando a ella se le antoja, llamando primero al caballero y echándolo después con el pretexto de la merienda. Indica a Xerez lo que debe hacer para que su plan salga bien, relegándola a ser mero testigo, que podrá reírse a escondidas y comprobar lo falso del amor cortés. Adelanta lo que va a ocurrir al describir las actitudes contradictorias del amante cortés antes, incluso, de que él suba y las manifieste. Sabe perfectamente, como buena conocedora de todos los tópicos de la poesía cancioneril, cómo se va a comportar y qué va a decir su enamorado en todo momento. Esto es, está situada en una esfera superior -aunque Puertocarrero suba físicamente ante ella, ésta siempre está por encima-, controlando constantemente el desarrollo de la obra, en ese papel omnisciente que le otorga lo previsible de un personaje como el del caballero, perfectamente intercambiable por cualquier otro amante cortés.

La protagonista de las Coplas se sale, claramente, de su molde ya que, a pesar de presentar la dureza y la defensa del honor propia de estas damas, su descarado realismo y su pícara inteligencia, la alejan de la seriedad o gravedad con que se ofrecen estos personajes femeninos en obras como la Cárcel de amor de San Pedro o la Querella ante el Dios de Amor de Escrivá. El adjetivo "donosa" con que la define Xerez (v. 26) va bien al tono burlesco de su plática, pues es a través del lenguaje como muestra, realmente, su superioridad sobre Puertocarrero. Con una gran dosis de guasa suelta ese "n'ós huya el conejo: acordáos que es refrán viejo", que aconseja a Puertocarrero desistir de su amor por ella. Rompe con lo esperado en una dama que acaba de oír la serie de retruécanos y juegos de palabras que manifiestan la adoración que el caballero le profesa y lo lamentable de su estado, al ser siempre rechazado. Ella ataja continuamente, con ágiles y punzantes observaciones, la extensa retórica cortés de su enamorado, caracterizada por todas las figuras propias de la poesía de cancionero (paradojas, encadenamientos de palabras y conceptos, metáforas, símiles...), utilizando expresiones breves que frenan en seco la charla interminable y repetitiva de su interlocutor: 


$\begin{array}{ll}\text { Puerto Carrero } & {[\ldots] \text { Sufro el desseo de veros }} \\ & \text { Y en veros desseo oíros, } \\ & \text { y en oíros conoceros, } \\ \text { donde m' es fuerça serviros. } & \text { Serviros cresce el desseo, } \\ & \text { y el dessear } \\ & \text { me haze desesperar } \\ & \text { de la gloria que posseo } \\ & \text { quando cabe vos me veo... } \\ & \text { ¿Vos habláis? }\end{array}$

(vv. 397-414)

Los apelativos despectivos hacia Puertocarrero y los imperativos despidiéndolo o proclamando su insensatez, son frecuentes y dan cuenta del dinamismo de algunas escenas: "quitá el pie del escala y volveos", "Ios, que sois enojoso", "guardá allá", "Iós d'aí, no me enojéis”, “callad ya”, “¡Ieshú qu’emportuno estáis!”...

Ese hartazgo que muestra desde el principio, la mantiene en la cruel y desdeñosa ignorancia hacia el caballero, al que probablemente ni miraría, yendo de un sitio a otro, con el fin de ningunear su dolor y menospreciar sus requerimientos. La dama se rebela, así, contra el estatismo de un Puertocarrero, que tras subir por la escala y plantarse ante ella, apenas parece moverse, extasiado y dolorido. Puertocarrero espera en vano que su bella dama quede inmóvil en su pedestal, para poder adorarla con comodidad, tal y como establecen las normas corteses. La viveza y el dinamismo de Ella lo desconciertan tanto que llega, incluso, a "perder los papeles" y, frente a tanto elogio aprendido, llega a insultarla tachándola de "descortés":

Y aún no hize la levada

de lo qu'es,

y vos, dama descortés, sin ser la salva acabada, dais la mesa por alçada. (vv. 374-378)

Monica von Wunster (1996: 35) muestra, precisamente, la importancia de este adjetivo para definir el comportamiento de una dama que impide a su caballero realizarse como amante cortés, que no lo deja actuar y expresarse como mandan las reglas del juego cortesano:

Le fatiche dello sventurato amante vengono accostate alla scuola, alla música, al torneo, alla religione, alla scherma ed al banchetto. Tutte aqueste occupazioni fanno parte del mondo cortese: sono gli impegni del cavaliere-cortigiano che debe essere istruito, saper combattere, essere un buon credente e partecipare alla vita di corte. Ma nel caso del nostro cavaliere non una di queste acttività va a buon fine, si trata di un elenco di tentativi frustrati a causa dell'atteggiamento della dama, la quale, di conseguenza viene qualificata con l'aggettivo descortés.

A la necesidad de Puertocarrero de analizar por extenso su pasión para convencerla de su amor, de acercarse a ella tanto física como espiritualmente -y, además, 
sin mostrar ninguna prisa, ya que se halla ante su más gloriosa visión ("el bien de miraros bien sufre el mal de todo el año")-; la dama opone la concentración expresiva, la rapidez, el nerviosismo y el rechazo físico ("estad, noramala quedo", "Ihesú, de vos me defiendo"...) de quien desea acabar cuanto antes con tan pesado visitante.

Esa tensión producida por ese juego de acercamiento-huida, de análisis-síntesis expresiva, de demora-prisa que se produce entre los dos personajes, es muy teatral. Podemos imaginar a Ella haciendo burlescos ademanes a Xerez para que se esconda, mirando por la ventana para ver que ya es tarde, o dando vueltas por la sala para buscar su "dechado" mientras pregunta, inquieta, a la tercera por él, sin preocuparse ya de que la mandó esconderse. O moverse de un sitio a otro en la preparación de los manteles para la merienda, mientras llama a gritos a Leonorcica, a la que trata violentamente de "vellaca", ejerciendo caprichosamente la superioridad que le otorga su estatus de dama noble frente a una criada y a un "servidor" ya vencido y burlado. Gracias al protagonismo y movimiento del personaje femenino y a sus secas y cortantes intervenciones, el texto gana, sin duda, en dinamismo y logra salir del estatismo propio del debate amoroso.

Manuel Moreno (2001:16) destaca la teatralidad de la versión del Cancionero de Londres sobre la del Cancionero General argumentando que la escena en que se desenvuelve el diálogo es un patio, con sus galerías, frente a la calle que se menciona en la del Cancionero General y el lugar impreciso donde ocurre la acción. Se refiere, además, a la gran variedad de tonos: sentencioso, coloquial, retórico..., que se suceden a lo largo de la obra y que dan lugar a diferentes y variados sentimientos, para justificar el dinamismo de las Coplas. Sin embargo, podríamos matizar que, en esa diversidad de discursos y cambios emocionales, Ella, con su frescura verbal y agilidad escénica, tiene mucho que decir. El personaje femenino, tanto en la versión del Cancionero General como en la del Cancionero de Londres, es, en definitiva, elemento esencial en la consecución de la teatralidad del texto. No hay sino comparar a Ella con otras voces femeninas que aparecen en los diálogos amorosos de los cancioneros castellanos del XV.

\section{Ella frente a las voces femeninas de otros diálogos amorosos de cancionero}

\subsection{Fernán Sánchez Calavera [ID 1663] y [ID 1664]}

Podemos comparar el personaje de Ella con las respuestas femeninas al galán de dos dezires de Fernán Sánchez Calavera, que aparecen recogidos en el Cancionero de Baena. La primera de estas composiciones [ID 1663] incluye un encabezamiento que reza: "Este dezir fizo e ordenó el dicho Ferrand Sánchez Calavera por contemplaçión de una su linda enamorada, en el cual dezir va relatando él su entençión a ella, e va ella respondiendo a él a cada cosa de lo que dize, e danse de los escudos el uno al otro como en gasajado de motes" (Dutton y González Cuenca, 1993: 409-410) y ha sido calificado por Ana Rodado (1995: 27-44) como "texto semidramático", basándose en una serie de elementos destacados por Sirera (1992: 351-363): el diálogo entre dos o más personajes, la acción, la presencia de acotaciones escénicas, las indicaciones espacio temporales y de vestuario y atrezzo. 
El segundo dezir de Calavera [ID1664], presenta igualmente un personaje femenino que responde a los requerimientos del poeta enamorado y es introducido por las siguientes palabras: "Este dezir fizo e ordenó el dicho Fernand Sánchez Calavera como en manera de preguntas e reqüestas que fazía e ponía contra una señora de qu'él andava muy enamorado. El qual decir va muy bien fecho por quanto en la una copla dize él contra ella la entençión de sus amores e respóndele ella luego en otra copla, defendiéndose d'él muy bien" (Dutton y González Cuenca, 1993: 410-412).

Como las Coplas de Puertocarrero, estos dos dezires amorosos de Calavera presentan el rechazo que sufre un experimentado amante cortés por parte de una inteligente y firme dama, que logra derrotarlo dialécticamente. Haciéndose eco, curiosamente, de ese consejo que otro destacado poeta de cancionero, Pedro de Cartagena, diera a las damas de la corte sobre los engaños de los galanes, desmontando esos falsos ademanes corteses con dureza e ironía:

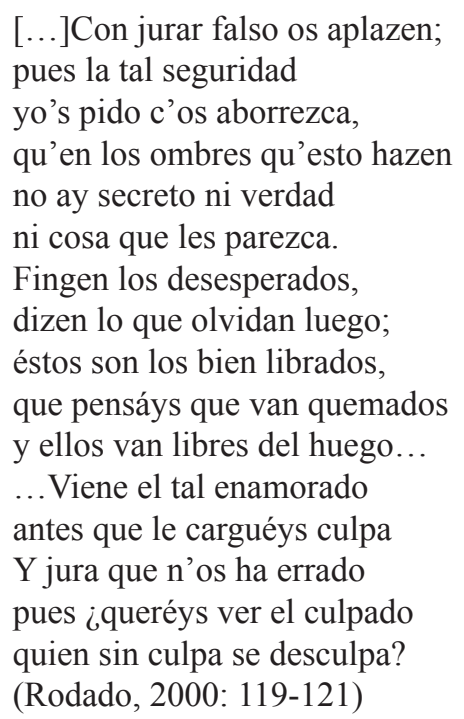

En el primero de estos textos de Calavera, nos encontramos, así, con seis coplas de arte menor en las que se produce un dinámico y animado diálogo entre un cortés galán y una dama desengañada que, si en otro tiempo se dejó seducir por él, ya no cree ni uno solo de sus requiebros.

La primera copla nos narra en primera persona la situación en que se produce el encuentro entre estos dos personajes:

Fui a ver este otro día, estándome de vagar, una señora que amar en algund tiempo solía. (vv. 1-4)

Y acto seguido, esta voz en primera persona del personaje masculino -encarnación de ese caballero cortesano ocioso que en tiempos de paz encuentra diversión en 
el cortejo amoroso-, nos va a introducir el diálogo que mantiene con esta "señora", marcando las intervenciones de cada uno:

Fablela en cortesía, dixe: "Dios vos mantenga"

Ella dixo: "muy bien venga

el que venir non devía".

(vv. 5-8)

El discurso femenino, por tanto, se nos ofrece a través de la voz y de la perspectiva de su rival masculino en esta riña amorosa.

La voz narrativa en primera persona del protagonista desaparece, no obstante, en las siguientes tres coplas, donde se produce una rápida alternancia entre el galán y la dama de forma directa y viva, sin tener ninguno de los parlamentos una extensión prefijada, aunque vienen caracterizados por la brevedad, ya que oscilan entre uno, dos o tres versos. El animado debate está plagado de imperativos, vocativos, exclamaciones y verbos de movimiento. Se produce, así, un clima de gran tensión entre el caballero, que pide su "galardón" y le reprocha a la dama su frialdad-sacando oportunamente a colación el que en otro tiempo fuera más cariñosa con él- y una mujer dolida y ya no tan inexperta ("de vuestro mal soy sana", v.12), que no quiere tener amores con quien siempre está fuera y, sobre todo, con quien corteja y ha cortejado a otras damas:

-Otro tiempo vi, señora, que mejor me reçebistes. -Vos mesmo lo mereçistes. ¡Andad, idvos en buen hora! $\mathrm{Al}$ que siempre fuera mora non lo quiero por amado. -Vuestro fui e soy de grado -Ya non vos cumple agora. -Non lo soliedes aver, mucho vos veo ser flaca.

-Non curedes de la vaca que non avedes de comer -Sería ledo en vos ver, Bien alegre e placentera.

-Id, que non soy la primera

Que fue loca en vos creer.

(vv. 19-32)

En la quinta copla vuelve a aparecer esta voz narrativa en primera persona del personaje masculino para introducir las intervenciones de los interlocutores y dar indicaciones sobre el movimiento escénico, en ese contacto físico que intenta el galán ("Alleguéme sonreyendo", v.35). Incluso, esta voz narrativa interpreta la actitud de la dama ante ese acercamiento suyo, que cuenta de la siguiente manera: 


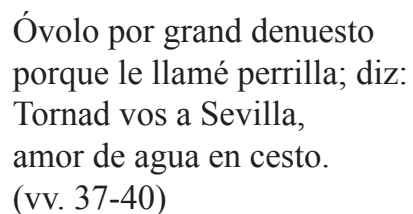

El empleo de dos refranes populares, que modifica interesadamente para sentenciar su rechazo: "Quien fue a Sevilla perdió su silla" y "Amor de niña, agua en cestilla", muestra un claro aire realista y un enfado muy humano. Se ofrece, así, un carácter femenino fuerte y orgulloso, que ha decidido no dejarse seducir de nuevo por quien no le conviene y por quien le ha dado, incluso, mala fama. En la última copla estalla esa indignación -que ha ido creciendo a lo largo del texto- y la dama usa de una violenta ironía de forma parecida a Ella en las Coplas de Puertocarrero:

-En seguir aquesta rama

parésceme que soy loco.

-¡Ay, amigo, e non de poco,

amar a quien no vos ama!

¡farta soy de mala fama!

(vv. 41-45)

Finalmente, un comentario imprudente del enamorado sobre su honra la hace soltar toda su agresividad y su rabia en los dos versos con los que acaba el poema:
¡Aí, Señor Dios, ansí
arda en fuego vuestra alma!
(vv. 47-48)

En el segundo Dezir de Calavera al que nos hemos referido, formado por diez coplas de arte mayor en tono grave y sentencioso, tenemos también el desdoblamiento del autor en dos voces -la del galán y la dama-, que se van alternando de forma ordenada y no encontramos ya ninguna voz narrativa. No obstante, su diálogo es menos ágil que el anterior, ya que cada intervención abarca rigurosamente una copla entera $\mathrm{y}$ tampoco ofrece referencias al contexto en que se produce, ni indica movimiento alguno. Con todo, podemos apreciar un aumento de la tensión en la novena copla, con las palabras llenas de ira y agresividad del varón contra la dureza de la dama, especialmente del verso 69 al 72, al saberse irremisible perdedor en este juego amoroso:

-Agora vos digo que puedo, señora, contarvos por más cruel e más dura de quantas conosco en el mundo agora nin de fallar puede en toda scritura. ¡Dóla al diablo atanta cordura! Siempre dezides al omne de non, más fortaleza tenéis que sansón, con vos no me vale razón nin mesura. (vv. 65-72) 
En este poema encontramos, a lo largo de todo él, el juego dialéctico entre el amor religioso, que representan las castas y piadosas palabras de la dama y el amor mundano, que representa cada parlamento del encendido galán. Éste comienza su intervención declarando a la dama su amor ("Señora muy linda, sabed que vos amo") y ensalzándola por su gentileza, su gracia y su alto linaje. La convierte, en definitiva, en ese prototipo de dama cortés, por cuyo amor se ennoblece el alma del enamorado. Pero ésta muestra, ya desde el principio, ese rechazo a los placeres mundanos, de acuerdo con los De contemptu mundi medievales; y -de forma harto radical-, al amor:

-Amigo, mirando aquel verde ramo que en el paraíso la Virgen alcança, en más poco tengo que paja nin tamo aqueste vil mundo e su buenandanza, que la que non ama bive en folgança

e su corazón en paz sin pensar, e quien Amor sirve suele alcanzar por poco plazer asaz tribulança.

(vv. 9-16)

El enamorado intenta disuadirla argumentando que es extraño que una dama tan bella no sienta ni haya sentido nunca la curiosidad de amar, como ocurre en las demás mujeres. Pues además, dada su corta edad, si lo hiciera y no saliera bien, tendría tiempo de sobra para arrepentirse y hacer penitencia. A lo cual vuelve a responder la dama con gran firmeza, enarbolando la sentencia que dice:

es más provechoso, segund vos sabedes, vençer al diablo quando echa sus redes que fecho el pecado, remedio poner.

(vv. 30-32)

Viendo que en el plano abstracto no puede convencerla y que, ante su férrea voluntad y su inclinación a la vida religiosa, queda totalmente desarmado, pasa al ámbito de lo concreto justo a la mitad de la composición -en la quinta copla-, ofreciéndose él mismo como amigo con el que puede conversar. Consciente de sus encantos osa, incluso, pedirle un beso (v.40). Intenta, con ello, ese acercamiento físico que también aparece en las Coplas de Puertocarrero y que se reduce, esta vez, a un intercambio de expresiones cortesanas. La dama reconoce, humildemente, sentirse indefensa ante su atractivo -ponderando ahora el poder de lo físico sobre lo espiritual- y, previsora del peligro, rechaza su ruego: "que mi corazón seríe conquistado/si vos consistiese llegar a mi faz" (vv. 45-46).

El galán se atreve, entonces, a dar un paso más en la séptima copla, insinuando que si en el futuro esta doncella cambiara de parecer y fuera perseguida por "las puntas de amor", seguiría hallando en él a un "leal servidor". A lo cual ella -sin abandonar ese tono mesurado y calmado que ha mantenido a lo largo de todo el debate-, le muestra nuevamente su firmeza y su rechazo. Pese a ser joven doncella, le hace saber que no cree en sus palabras con la recurrida metáfora de la caza de cetrería: "ca el dulce canto del gran bretador/ engaña e mata al ave cuitada" (vv.63- 
64); hecho que provocará esa subida de tensión, en la novena copla a la que nos hemos referido.

La dama tiene la misión de cerrar el poema con un tono grave y sentencioso, con ese golpe definitivo al personaje masculino que desenmascara -como la voz femenina del anterior poema-, su fama de burlador:

que non sé cristiana, judía nin mora

a quien vuestros dichos non pongan locura

maguer que de fuera demuestran dolçura

ençierran ponzoña en el corazón.

(vv. 75-78)

$\mathrm{Y}$ ese tono vuelve de lo concreto-individual al plano de lo abstracto-universal, con esa especie de advertencia o moraleja en contra de los hombres, recogida en un refrán y que invierte la visión de la mujer que hemos señalado, pasando ésta de ser la tentadora a ser la tentada, la víctima del engaño: “[...] Quien cree a varón/lágrimas siembra con mucha tristura" (vv. 79-80).

Si hemos dicho que el desengaño y el enfado de la voz femenina del primer dezir resultaba ciertamente realista y muy humano; la segunda dama, mucho más intangible, está envuelta en ese halo de ascetismo religioso que toma como modelo de fortaleza a la Virgen María, frente a las tentaciones del amor carnal que le ofrece el galán, identificado aquí con un diablo, con el pecado, con un falso "bretador". Estas voces femeninas, -ya desde la impulsividad de la primera, ya desde la piedad y mesura de la segunda-, contribuyen en gran medida a complicar la perspectiva y la voz en primera persona del sufridor enamorado. Sin embargo, no evolucionan a lo largo de la composición ni presentan ningún claroscuro: se limitan, con sus respuestas, a ser portavoces del autor, a desenmascarar, sin más, la falsedad de los usos amorosos corteses. Y, por supuesto, no consiguen -como sucede con Ella- sorprendernos con esa espontaneidad y viveza que llevan a la protagonista de las Coplas de Puertocarrero a escapar de su patrón literario y que la convierten en un personaje más verosímil y complejo.

\subsection{Johan de Duenyas [ID 2492]}

El Cancionero de Palacio recoge un poema dialogado de Johan de Duenyas (Álvarez Pellitero, 1993: 106-110), donde aparece una voz masculina $(\dot{E} l)$ y una voz femenina (Ella), en abierta disputa porque la dama se resiste a creer las palabras corteses del caballero. Este diálogo muestra, como sucede en las Coplas de Puertocarrero, a una mujer ingeniosa y astuta, cuya inteligencia es reconocida por la voz masculina en más de una ocasión:

Discreta senyora, tan savia vos siento e tanto avisada en todas las cosas que no sé que digua a vuestras graciosas paraulas tan savias que a mí dan tormento. (vv. 33-35) 
De esta forma, la dama de Duenyas -como la de las Coplas de Puertocarrerotambién llega a desmontar las frases aprendidas de fidelidad amorosa de su contrincante masculino con punzantes ataques de índole realista, basados en la experiencia:

E set bien seguro qu'el falso, maldito

Amor, no me ligue en tal ligadura;

que yo mesma havría a mí por locura, viendo esperiencia ser demostrada

quántas mudanças fazéys en hun hora, creher vuestros dichos de falsa dolçura.

(vv. 11-16)

$\mathrm{O}$, incluso, en un tono más directo y rotundo, quita a este varón ese orgullo cortés que lleva a elevar su amor por encima del de los demás: "Por muchos exemplos que oý/con todos los hombres vos hecho al rincón" (vv. 27-28).

Insiste en que, o bien hay que estar loca -como la que "siembra buen trigo en laguna" (v.30)-, o ser una ignorante -"más simple qu'estando en la cuna" (v.31)-, para creer en las palabras de un hombre. Con ello, se convierte en defensora de su sexo. No lucha solamente contra los engaños amorosos de este escudero, en concreto, sino de todo el género masculino; tal y como hacía Brazaida en la ficción de Juan de Flores frente a Torrellas ${ }^{6}$. Blay Manzanera (2000: 53) señala, además, que -como sucede en la narración del salmantino-, Johan de Duenyas llega a nombrar unos jueces para decidir quién lleva la razón: la mujer o el varón. Y, también como en la obra de Flores, la dama se queja de la parcialidad de estos jueces -hombres como su rival y, además, elegidos por éste-:
Mexor me sería que nunca nasciera cruel enemigo, que vos escuchar ni tant triste pleito con vos començar mas que no puedo ya partir afuera de tales juezes yo soy bien entera, a los quales pido qu'ayan conciencia e justamente que den su sentencia sin ser favorable, legítima, entera. (vv. 108-115)

Vemos, por tanto, que se sospecha perdedora no por su falta de méritos dialécticos, que ha demostrado anteriormente y que le habían dado cierta ventaja sobre el caballero, sino por la inferioridad con que socialmente era considerada la mujer. Se pliega, en consecuencia, al modelo cortés y pide solamente que no se sepa su nombre:

\footnotetext{
Brazaida proclama en Grisel y Mirabella: "si algunas con sano consejo, se apartan de oír vuestras engañosas hablas, no pueden apartarse de oír en las calladas noches el dulzor de los instrumentos y canto de la suave música, la cual para el engaño nuestro fue, por vos, inventada [...] aun en las encerradas cámaras do se esconden por no veros, con sotiles motes de sus siervas y cartas entráis. Y si ellas castigan sus mensajeras y rehúsan en no leer las cartas, cuando veis que, con las cosas dichas y otras infinitas, no las podéis empecer (porque puede más vuestra maldad y porfía que nuestra virtud), buscáis rodeos para dañar nuestras famas" (Archer, 2001: 243-244).
} 
Catat que esta es, señor, la primera cosa que mando por que vos digo que a senyor, pariente ni amigo, non se rebele mi nombre quál era.

(vv. 116-119)

En las Coplas de Puertocarrero, en cambio, el personaje femenino hace prevalecer su propio placer caprichosamente en un entorno que le es propicio: el de su propia casa, con la complicidad, además, de otra mujer, la tercera-confidente Xerez. Aunque en el exterior tuviera, como la dama de Juan de Duenyas las de perder, en este ambiente privado hace y deshace como le viene en gana. Si las convenciones la obligan, por ser mujer, a ser piadosa, prudente y recatada, el descaro que manifiesta en privado es -como hemos visto- algo que se sale de lo normal, por esa cómica agresividad con la que intenta deshacerse de su engorroso visitante: “¿No queréis acabar oy?/¡Qué postema!” (vv. 689-690).

En este texto de Duenyas, recogido en el Cancionero de Palacio, la burla no resulta tan cruel, sino que la dama se limita a recrear la queja que ya expresaron tanto algunas escritoras medievales - las trobairitz, Christine de Pizan...-, como personajes de ficción; así Brazaida o Fiometa en las narraciones de Juan de Flores ${ }^{7}$. Todas ellas denuncian la inconstancia masculina y el engaño al que someten a las inocentes mujeres muchos hombres experimentados, jurándoles un amor que no sienten con la sola intención de conseguir su virtud. Por ello, esta dama -dura e inconmovible, como un muro impenetrable-, responde siempre negando los requiebros del caballero y, enarbolando el sentido común, proclama que aunque pueda haber caballeros leales, no cree que a ella le vaya a tocar uno:

Senyor escudero, flaco çimiento

fazen en mí vuestras engenyosas

paraulas soptiles por ser enfintosas,

qu'en mí no farán jamás mudamento;

salvo que vengo en conocimiento

que hay muchos buenos de grant lealtança

e, obrando bien, mueren sin dubdança

mas d'estos yo dubdo ser una entre ciento.

(vv. 41-44)

\footnotetext{
Rosamaría Aguadé (2011: 23-43), señala que ya antes de la "Querelle des femmes" -movimiento en defensa de las mujeres que se desarrolló durante el S. XV; alentado por los escritos de Christine de Pizan a raíz de los ataques misóginos de la segunda parte del Roman de la Rose de Jean de Meun-, las trobairitz expresaron sentimientos femeninos muy cercanos a sus reivindicaciones. Y, concretamente, hay tensós donde, como ocurre en la Epistola del Dios de Amor de Pizan o en las mismas Coplas de Puertocarrero, la mujer se distancia irónicamente de la situación amorosa y desvela lo ridículo del galanteo masculino: "N'Elias Cairel,fegnedor/ resemblatz segon mon parer /com hom qui.s feing de dol aver/ de so dont non sent dolor" (Martinengo, 1997: 82, vv. 33-36). Esta idea, por tanto, desarrollada ampliamente por Christine de Pizan, de forma rigurosa, en $L a$ ciudad de las damas: "il n'est que trop certain que les hommes trompent frèquemment les femmes par leur ruse et leur duplicité" (Moreau et Hicks, 2000: 211), atraviesa prácticamente todo el Medievo, pudiéndose ver su reflejo, por ejemplo, en la Fiometa de Juan de Flores, trágica víctima de tal engaño, que increpa desesperada a Pánfilo: “ ¡O malo, malvado, cómo aquexavas dolor allí do no te dolía! Mirándote estoy y no sé donde escondías tantas artes para engañarme..." (Parrilla, 2008: 154).
} 


\subsection{Francisco Imperial [ID 1376]}

Estas voces de mujer evidencian su indefensión ante una sociedad que las margina; ante unos jueces, como sucede en la composición de Duenyas, que ya tienen emitido un veredicto favorable al varón. No les queda más opción, a veces, que la de tomarse la justicia por su mano. Hay, precisamente, un célebre dezir de Francisco Imperial recogido en el Cancionero de Baena [ID1376] (Dutton y González Cuenca, 1993: 293-294), en el que una doncella, tras acusar al poeta de traidor, le hiere con su arco, no sin antes avisarlo de su intención:

Los pechos albos, la garganta alçada,

la vide venir escontra el río con buen continente e graçioso brío, arco en la mano, frecha maestrada e dixo: "Escudero, de aquesta vegada del barco en tierra non desçendades, e si non, creo que vos repintades." Esto me dixo con voz delicada. Quando yo esto le oí decir, salté a tierra muy maravillado e ella tendió el arco maestrado, por sobre los pechos me fue ferir, e dixo: "Escudero, convién'vos morir, pues que por otra dexastes a mí, e yo faré que desde aquí vos nunca seades para otra servir". (vv. 9-24)

También Ella, en las Coplas de Puertocarrero, toma valientemente las riendas de la contienda amorosa y avisa al caballero cuando aún está subiendo por la escala, del resultado de su conversación:

$\begin{array}{ll}\text { Puerto Carrero } & \text { ¿Vuestra merced, qué me manda? } \\ \text { Ella } & \begin{array}{l}\text { ¿Qué? Que muráis de mala muerte, } \\ \text { o que viváis de tal suerte } \\ \text { que huyáis vuestra demanda. }\end{array} \\ \text { Puerto Carrero } & \text { Luego, ¿morir me mandáis? } \\ \text { Ella } & \text { Yo no lo hago, } \\ & \text { pero levaréis en pago } \\ & \text { de la pena que mostráis } \\ & \text { revés de lo que buscáis. } \\ & (\text { vv. 118-126) }\end{array}$

Ella no hiere al caballero con una flecha, sino con las palabras de la razón, que desmontan todo lo que él representa y provocan bien la muerte o bien la desaparición de ese amor desgraciado, el cual sólo puede traerle un sufrimiento gratuito. No actúa movida por una pasión y unos celos descontrolados, como la muchacha sevillana de Imperial -que luego revela que su flecha es de amor, pasando al plano alegórico, en 
la línea de "El triunphete de amor" del Marqués de Santillana ${ }^{8}$. Muy al contrario, la mueve un frío raciocinio que pretende acabar con los absurdos del sentimentalismo cortés. Pero, tal vez, Ella, con su actuación egoísta y descarada, con su violento dinamismo y la humillación que imprime a Puertocarrero, no sea en el fondo tan malvada y lo libere de esa prisión en la que se ha metido probablemente por mero capricho o moda. Recordemos que los ademanes caballerescos, de los que no pocos autores se burlan a fines del Medievo, no eran las más de las veces más que flirteos que no escondían sentimientos sinceros ${ }^{9}$.

\subsection{Fray Diego de Valencia de León [ID 1639]}

No es la protagonista de las Coplas de Puertocarrero la primera que advierte a un amante cortés de lo vanas que son sus penas. Así, en el Cancionero de Baena aparece un poema de fray Diego de Valencia de León [ID1639], introducido por las siguientes palabras: "Este decir fizo el dicho fray Diego como a manera de baldones que le dava una dueña que era su enamorada e non lo preçiava" (Dutton y González Cuenca, 1993: 357). En él encontramos una voz femenina que advierte al amigo de lo inútil que son sus requiebros con ella y que su perseverancia sólo puede conducirlo a la locura:

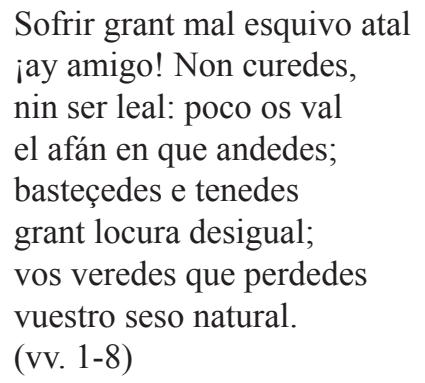

En estos versos de fray Diego de Valencia no encontramos ninguna reivindicación femenina, ni ningún reflejo de la situación o el pensamiento de la mujer, sino sólo la perspectiva del eclesiástico moralista, que quiere hacer prevalecer la razón, ante tanta incongruencia y desatino que, su parecer, entraña el lenguaje y el comportamiento del amante cortés:

Entençión muy sin razón

basteçedes todavía;

En este decir narrativo de Santillana, el poeta asiste curioso a un mitológico desfile primaveral guiado por Cupido y Venus, donde ricamente ornamentados aparecen hombres y mujeres de la Antigüedad, todos grandes amadores, y es herido por deseo de la diosa por "una dona muy notable" con una flecha de amor, que lo sume, a partir de ese momento en la tristeza y el dolor: "Así ferido a muerte/de la flecha infiçionada,/de golpe terrible e fuerte,/que de mí non sope nada,/por lo qual fue ocultada/de mí la visión que vía,/e tornóse mi alegría/en tristeza infortunada" (Pérez Priego, 1999: 260, vv. 153-160).

$9 \quad$ Vélez Sainz (2013: 48-67) insiste en que el servicio cortés se convierte en el S.XV en una praxis para los nobles que buscan la promoción política dentro de la corte prebendista de Juan II, y un buen ejemplo de ello es don Álvaro de Luna. Por tanto, como reflejo de esa realidad, donde los nobles se comportaban como los personajes de las ficciones caballerescas y sentimentales, encontramos no pocos ejemplos literarios que muestran, en tono crítico y burlesco, la vacuidad de unos ademanes amatorios más aprendidos que sentidos. 


\author{
finiçión es perdición \\ de vuestra loca porfía \\ bien sería e complería \\ sosegar el coraçón, \\ grant follía e fallía \\ fazedes sin condición. \\ (vv. 25-32)
}

La diferencia con la protagonista de las Coplas de Puertocarrero, caracterizada -como hemos dicho-, por su ambigüedad, su agilidad verbal y su egoísta proceder, es aquí abismal. La voz de mujer que utiliza fray Diego para dar su lección, es totalmente ajena al mundo femenino y no muestra ningún atisbo de individualidad. Sin embargo, Ella no se limita a ser la portavoz de las ideas de su autor, sino que penetra en el sentir de las mujeres de la época, haciéndose más concreta y tangible. Muestra la abierta batalla de sexos que se desarrolla a lo largo de todo el Medievo, desde su propia perspectiva femenina, y no duda en hacer prevalecer sus gustos y caprichos, sobre lo esperable socialmente en la educación de una dama cortés. De ahí que no le importe que Puertocarrero la ataque por su falta de piedad:

\begin{tabular}{|c|c|}
\hline Puerto Carrero & $\begin{array}{l}\text { No es mi muerte mi pasión, } \\
\text { es miraros } \\
\text { olvidar de acordaros } \\
\text { que avéis sido la ocasión } \\
\text { de mi fin y perdición. }\end{array}$ \\
\hline Ella & ¿Vistes qué se me da a mí? \\
\hline Puerto Carrero & Luego, ¿no tenéis conciencia? \\
\hline Ella & $\begin{array}{l}\text { No la tengo, aved paciencia. } \\
\text { (vv. } 518-525 \text { ) }\end{array}$ \\
\hline
\end{tabular}

\section{Conclusiones}

Si los escritos moralizantes eran, por lo general, bastante misóginos pues, en su rechazo del amor hereos, abominaban de esa mujer seductora, que traía la perdición del hombre; la perspectiva que el autor de las Coplas proyecta sobre Ella, podría considerarse pro-feminista. El personaje evidencia, así, la familiaridad de muchas damas nobles con la literatura, en tanto que grandes consumidoras de ficciones sentimentales y caballerescas y activas participantes en los espectáculos y fiestas palaciegas. A veces, incluso, se revelaron como creadoras de versos llenos de ingenio ${ }^{10}$. En

10 Recordemos a doña Leonor Centellas, doña Marina Manuel, doña Catalina Manrique, doña Isabel de Vergara, la reina Juana de Avis - esposa de Enrique IV-, o la dama Vayona. Y, especialmente, los versos de amor conyugal de doña Mayor Arias o la sinceridad desgarradora de la poesía de Florencia Pinar (Whetnall, 1984; Pérez Priego, 1990). La misma princesa Isabel participó, junto con otras jóvenes castellanas, en el momo que Gómez Manrique compuso para homenajear a su hermano Alfonso ( Álvarez Pellitero, 1990: 133-139; Surtz, 1992: 95-101; Pérez Priego, 2009: 150-155), contribuyendo a crear ese ambiente tan propicio para el lucimiento femenino al que se llegará en la corte de los Reyes Católicos, donde existía un círculo de mujeres ilustradas en torno a la reina -las puellae doctae-; admiración de maestros italianos como Lucio Marineo Sículo, que en su Hispanis 
este sentido, Ella está capacitada para jugar al juego del amor cortesano en igualdad de condiciones que el varón. Pero, sobre todo, debido a su gran conocimiento de la literatura cortés, presenta una astuta táctica de juego: analiza primero y rompe después el molde femenino esperado, descolocando a su adversario.

Cuando Ella decide caprichosamente acabar con el juego, quitándose la máscara de dama y proclamando, abiertamente, su interés real y concreto por la merienda, el choque con el etéreo mundo cortés de Puertocarrero, que se resiste a dejar su fingimiento y se regodea en su sacrificio amoroso - a imitación de caballeros reales como Suero de Quiñones; o literarios, como el sufrido Leriano de San Pedro-, resulta brutal. Ella actúa entonces, y sin ningún pudor, como ese tipo de mujer que describe el Arcipreste de Talavera "franca en pedir e demandar [...], cavilosa en la mano alargar [...], abondosa en cualquier cosa tomar" (Ciceri, 1990: 169). Esto es, como un prototipo de la literatura realista, situado en las antípodas de la perfecta y alta dama cortés. Y, por supuesto, lo que pierde en nobleza lo gana en espontaneidad y verosimilitud, mostrando una imagen de la mujer más cercana y también más valiente, al atreverse a reivindicar sus propios intereses. Aunque, al fin y al cabo, dado su gusto por la chanza, también parece adoptar la pose de este tipo popular de mujer para molestar - o tal vez para desenamorar- a su interlocutor, envuelta en esa ambigüedad entre la crueldad y la compasión a la que nos referíamos.

En definitiva, la dama de las Coplas de Puertocarrero consigue elevar la importancia de la voz femenina en la literatura cuatrocentista, concediendo a ese símbolo de belleza que representa, una inusual viveza y desenvoltura. Su peculiar victoria sobre el amante a través de la razón y de la pericia argumentativa y verbal, la sacan, sin duda, de ese silencio al que se condenaba, generalmente, a la mujer medieval. Con su pícara ironía, con sus salidas secas y cortantes, o con su "mala educación" -si se quiere-, consigue huir de ese papel de belle dame sans merci al que las convenciones de la literatura medieval la hubieran relegado -como cruel "enemiga" de lo humano-. Pero también consigue escapar del simple rechazo del amor cortés que buscaban las voces femeninas de los debates amorosos analizados, al ser un personaje mucho más complejo, que se mueve orgullosa y violentamente en escena, capaz de razonar, de avanzar y retroceder en sus argumentos, de inventar y llevar a cabo un ardid -como después harán ciertas damas de la Comedia Nueva-; con una entidad dramática, en fin, clara e independiente. Y proclama, ante la amanerada vida cortesana de finales del Cuatrocientos, la necesidad de un amor más sincero, concreto y directo:

Dexad las comparaciones

y quexad lo que sentís,

porque cuanto me decís

todo pasa entre renglones.

Tomáis unas conclusiones

de penar;

de no saberos quexar

o de falta de pasiones,

os fallescen las razones.

(vv. 379-387)

Laudibus proclama que las damas españolas son "elocuentes y sin complejos ante los hombres, en quienes ven sus iguales" (Márquez de la Plata, 2005: 14). 


\section{Obras citadas}

Aguadé Benet, Rosamaría, «Christine de Pizan y las trobairitz: miradas entrecruzadas frente a la fin'amors», en Segura Graíño, Cristina (coord.), La querella de las mujeres III. La querella de las mujeres antecedente de la polémica feminista, Madrid, Al-Mudayna (Querella-Ya), 2011, pp. 23-43.

Álvarez Pellitero, Ana $\mathrm{M}^{\mathrm{a}}$ (ed.), Teatro medieval, Madrid, Espasa-Calpe (Austral, A157), 1990.

Álvarez Pellitero, Ana Ma (ed.), Cancionero de Palacio, Salamanca, Biblioteca Universitaria de Salamanca/ Junta de Castilla y León. Consejería de Cultura y Turismo, 1993.

Archer, Robert, Misoginia y defensa de las mujeres. Antología de textos medievales, Madrid, Cátedra (Feminismos, 63), 2001.

Blay Manzanera, Vicenta, «El discurso femenino en los Cancioneros de los siglos XV y XVI», en Sevilla Arroyo, Florencio y Carlos Alvar Ezquerra (coords.), Actas XIII Congreso AIH, Madrid 6-11 julio de 1998 (Tomo I), Madrid, Castalia, 2000, pp. 48-58.

http://cvc.cervantes.es/literatura/aih/pdf/13/aih_13_1_011.pdf

Blecua, Alberto (ed.), Juan Ruiz, Arcipreste de Hita, Libro de buen amor, Madrid, Cátedra (Letras Hispánicas, 70), 1998.

Ciceri, Marcela (ed.), Alfonso Martínez de Toledo, Arcipreste de Talavera, Madrid, Espasa-Calpe (Austral, A 95), 1990.

Dutton, Brian y Joaquín González Cuenca (eds.), Cancionero de Juan Alfonso de Baena, Madrid, Visor Libros, 1993.

Lázaro Carreter, Fernando (ed.), Teatro medieval, Madrid, Castalia, 1965.

Le Goff, Jacques, La civilización del occidente medieval, Barcelona, Paidós, 1999 (5 reimpresión).

Márquez De La Plata Y Ferrándiz, Vicenta $\mathrm{M}^{\mathrm{a}}$, Mujeres renacentistas en la corte de Isabel la Católica, Madrid, Castalia, 2005.

Martinengo, Marirì, Las trovadoras. Poetisas del amor cortés, Madrid, horas y HORAS la editorial (Cuadernos Inacabados, 28), 1997.

Moreau, Thèrese et Éric Hincks (eds.), Christine de Pizan, La cité des dames, Paris, Stock (Moyen Âge), 2000.

Moreno Sanjuán, Manuel, «Teatro cortesano en los cancioneros castellanos: otra versión de las Coplas de Puertocarrero», Revista de Literatura Medieval, 12 (2001), pp. 9-53.

http://dspace.uah.es/dspace/handle/10017/10321

Parrilla, Carmen (ed.), Juan de Flores, Grimalte y Gradisa, Alcalá de Henares, Centro de Estudios Cervantinos, 2008.

Pérez Priego, Miguel Ángel, Poesía femenina en los cancioneros, Madrid, Castalia/Instituto de la Mujer (Biblioteca de Escritoras), 1990.

Pérez Priego, Miguel Ángel (ed.), Marqués de Santillana, Poesía lírica, Madrid, Cátedra (Letras Hispánicas, 475), 1999.

Pérez Priego, Miguel Ángel (ed.), Teatro Medieval, Madrid, Cátedra (Letras Hispánicas, 646), 2009.

Rodado Ruiz, Ana, «Poesía cortesana y teatro: textos semidramáticos en los cancioneros cuatrocentistas», en Pedraza, Felipe B. y Rafael González Cañal (eds.), Los albores del teatro español: Actas de las XVII Jornadas de Teatro Clásico, julio 1994, Almagro, Festival de Almagro/Universidad de Castilla-la Mancha, 1995, pp. 25-44. https://www.uclm. es/centro/ialmagro/publicaciones/pdf/CorralComedias/5_1994/4.pdf 
Rodado Ruiz, Ana, Poesía. Pedro de Cartagena, Cuenca, Ediciones de la Universidad de Castilla- La Mancha, 2000.

Sirera, José Luis, «Diálogos de cancionero y teatralidad», en Historia y ficciones. Coloquio sobre literatura del Siglo XV, Valencia, Universidad de Valencia, 1992, pp. 351-363.

Surtz, Ronald E. (ed.), Teatro castellano de la Edad Media, Madrid, Clásicos Taurus-13, 1992.

Vélez Sainz, Julio, «De amor, de honor e de donas». Mujer e ideales corteses en la Castilla de Juan II (1406-1454), Madrid, Editorial Complutense, 2013.

Whetnall, Jane, «Lírica femenina in the Early Manuscript Cancioneros», en Salvador Bacarisse et al. (eds.), What's Past is Prologue: A Collection of Essays in Honour of L.J. Woodward, Edinburgh, Scottish Academic Press, 1984, pp.138-150.

Wunster, Monica von, «Le coplas di Puertocarrero e la smitizzazione del codice cortese», en Scrittori «contro»: modelli in discussione nelle letterature iberiche. Atti del Convegno di Roma (15-16 marzo, 1995), Roma, Bulzoni Editore, 1996, pp. 31-40. http://cvc.cervantes.es/literatura/aispi/pdf/07/07_029.pdf 